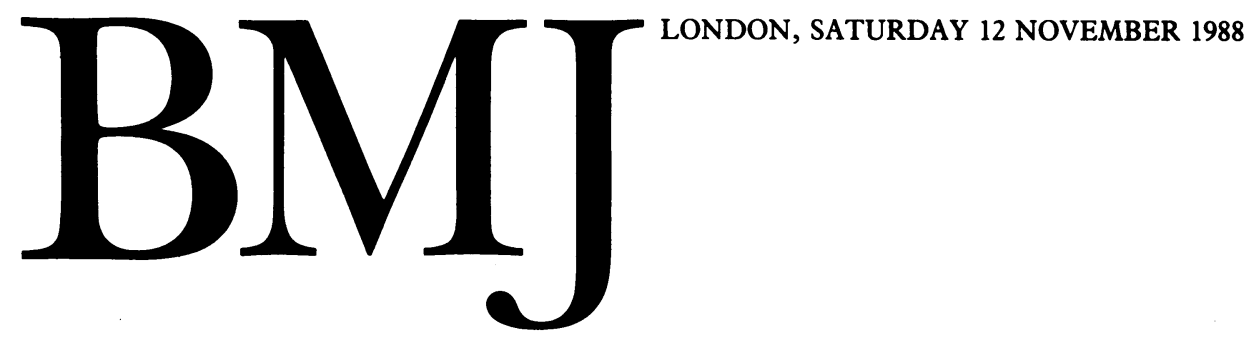

\title{
Overdiagnosing hypertension
}

\section{A fifth of patients with borderline hypertension may be treated unnecessarily}

We are probably misdiagnosing and overtreating hypertension. In the United States about 58 million people are hypertensive and about 35 million have blood pressures that would qualify them for drug treatment. ${ }^{1}$ Once started the treatment will usually be continued for life, at the estimated yearly cost of $\$ 18$ billion to $\$ 21$ billion, including professional fees and laboratory tests. ${ }^{2}$ If even one quarter of these treated patients have been misdiagnosed the financial savings have been estimated at about $\$ 5$ billion each year. But additionally there are the costs of the adverse effects of misdirected treatment and the personal consequences of being mislabelled "hypertensive" - worry and effects on employment prospects, pension, and insurance rights.

We do have, however, evidence that high blood pressure is a major risk for cardiovascular disease ${ }^{3}$ and that lowering blood is beneficial. ${ }^{46} \mathrm{We}$ are not denying such evidence in persisting with the view that we may well be overtreating hypertension: if we tip more and more people with hypertension into the epidemiological stew the analysis of risk may be diluted but just as conclusive. Nevertheless, those treated unnecessarily have nothing to gain, and lowering blood pressure too much may in itself be harmful. ${ }^{\text {? }}$

The evidence that we are overdiagnosing hypertension comes from techniques for measuring ambulatory blood pressure. ${ }^{8}$ As long ago as 1904 Theodore Janeway, writing before Korotkoff had reported the now accepted auscultatory method of measuring blood pressure, showed that stress could raise blood pressure. ${ }^{9}$ Smirk endeavoured to remove the effects of such stresses by measuring basal blood pressure, ${ }^{10}$ and several researchers over the years have cautioned against the excessive diagnosis and treatment of hypertension. ${ }^{11} 12$ Though self measurement of blood pressure has been shown to give values substantially lower than those measured in the hospital clinic or family practitioner's surgery, ${ }^{13}{ }^{14}$ the practice has never become popular in the United Kingdom and Ireland. The technique did emphasise, however, the limitations of the casual measurement of blood pressure.

The development of non-invasive techniques for measuring ambulatory blood pressure has made it possible to study blood pressure as it changes, which offers advantages over the conventional practice of measuring it sporadically, often under artificial and stressful circumstances, by a technique replete with potential inaccuracies. ${ }^{15}$ It soon became evident that ambulatory measurement gave lower readings than blood pressure measured by family practitioners, ${ }^{5}$ hospital staff, and patients themselves. ${ }^{16}$ Moreover, the technique may predict cardiovascular morbidity and mortality more accurately than the casual measurement of blood pressure..$^{18} 19$

The patients at risk of being misdiagnosed are those with borderline hypertension, in whom ambulatory blood pressures may be considerably lower than those recorded in surgeries or clinics. This phenomenon, in which high pressures recorded by conventional techniques are subsequently shown by ambulatory measurement to be normal has been named "white coat hypertension." 20 In a recent study Pickering et al found white coat hypertension in $22 \%$ of 292 patients with borderline hypertension. ${ }^{21}$ In other words, almost one quarter of their patients in whom borderline hypertension had been diagnosed had normal ambulatory blood pressures. In a retrospective study of 638 patients with hypertension in our unit $89 \%$ satisfied the World Health Organisation's criteria for having hypertension, but only $46 \%$ would have been judged hypertensive by ambulatory measurement. ${ }^{17}$

These findings have considerable implications for managing hypertension, and two multicentre European studies are about to start to assess further the use of ambulatory blood pressure measurement in managing hypertension and determining its prognosis. Though it will be some time before these studies yield results, doctors cannot ignore the implications of ambulatory measurement of hypertension. Faced with a patient with borderline hypertension, the doctor should be slow to diagnose hypertension until some attempt has been made to categorise the behaviour of blood pressure over time; ambulatory blood pressure measurement is the best way to do this.

EOIN O'BRIEN Consultant Cardiologist

KEVIN O'MALLEY

Professor of Clinical Pharmacology

The Blood Pressure Unit,

Beaumont Hospital,

Dublin 9

1 Subcommittee on Definition and Prevalence of the 1984 Joint National Committee. Hypertension prevalence and the status of awareness of treatment, and control in the United States: final report. Hypertension 1985;7:457-68.

2 Medical Technology and Practice Patterns Institute. Hypertension: questions of prevalence, diagnosis, and management. Fournal of Clinical Hypertension 1987;3:757-67.

Kannel WB. The role of blood pressure in cardiovascular morbidity and mortality. Prog Cardiovasc Dis 1974;17:5-23.

4 Hypertension Detection and Follow-Up Program Cooperative Group. Five-year findings of the hypertension detection and follow-up program. I. Reduction in mortality of persons with high blood pressure, including mild hypertension. FAMA 1979;242:2562-71.

5 Management Committee of the Australian Therapeutic Trial in Mild Hypertension. Untreated mild hypertension. Lancet 1982;i:185-91. 
6 Medical Research Council Working Party. MRC trial of treatment of mild hypertension: principal results. Br Med f 1985;291:97-104.

Cruikshank JM, Thorp JM, Zacharias FJ. Benefits and potential harm of lowering high blood pressure. Lancet 1987; $581-4$.

8 Pickering TG, Harshfield GA, Kleinert HD, Blank S, Laragh JH. Blood pressure during normal daily activities, sleep, and exercise. Comparison of values in normal and hypertensive subjects. IAMA 1982;247:992-6.

9 Janeway TC. The clinical study of blood pressure. A guide to the use of the sphygmomanometer. New York: D Appleton, 1904:120.

10 Smirk FH. Casual and basal blood pressures. IV. Their relationship to the supplemental pressure with a note on statistical implications. Br Heart $\mathcal{F}$ 1944;6:176-82.

11 O'Brien E, Fitzgerald D, O'Malley K. Blood pressure measurement: current practice and future trends. Br Med f 1985;290:729-34.

2 Waeber B, Scherrer U, Petrillo A, et al. Are some hypertensive patients overtreated? A prospective study of ambulatory blood pressure recording. Lancet 1987;ii:732-4.

13 Fitzgerald D, O'Callaghan W, O'Brien E, Johnson H, Mulcahy R, Hickey N. Home recording of blood pressure in the management of hypertension. Ir Med f 1985;78:216-8.
14 Julius S, Ellis CN, Pascual AV, et al. Home blood pressure determination. Value in borderline ("labile") hypertension. ҰAMA 1974;229:663-6.

15 O'Brien E, O'Malley K. ABC of blood pressure measurement: technique. Br Med $\mathcal{f}$ 1979; ii:982-4.

16 Flapan AD, Stewart SE, McDougal F, Padfield PL. Is self home-monitoring of blood pressure as good as 24-hour ambulatory monitoring? I Hypertens [Suppl] 1987;5:491-3.

17 Kenny RA, Brennan M, O'Malley K, O'Brien E. Blood pressure measurements in borderline hypertension. $\mathcal{F}$ Hypertens [Suppl] 1987;5:483-5.

18 Perloff $\mathrm{D}$, Sokolow $\mathrm{M}$, Cowan $\mathrm{R}$. The prognostic value of ambulatory blood pressure. JAMA 1983;249:2792-8

19 Devereux RB, Pickering TG, Harshfield GA, et al. Left ventricular hypertrophy in patients with hypertension: importance of blood pressure response to regularly recurring stress. Circulation 1983;68:470-6.

20 Pickering TG, Devereux RB. Ambulatory monitoring of blood pressure as a predictor of cardiovascular risk. Am Heart f 1987;114:925-8.

21 Pickering TG, James GD, Boddie C, Harshfield GA, Blank S, Laragh JH. How common is white coat hypertension? JAMA 1988;259:225-8.

\section{Overtreating hypertension}

\section{Mortality from coronary artery disease may be increased if pressures are dropped too low}

Doctors have long been anxious that they may do more harm than good when treating mild hypertension. Rapid reductions of blood pressure may precipitate stroke, myocardial infarction, or a deterioration in renal function ${ }^{1-3}$; this has led to the disappearance of parenteral antihypertensive drugs except for use in patients with hypertensive encephalopathy. Some have worried that over enthusiastic treatment in elderly hypertensive patients with oral drugs might also precipitate cerebral underperfusion, ${ }^{45}$ and in 1979 an alarming increase in the relative risk of coronary heart disease was reported in hypertensive patients whose diastolic pressures were reduced to below $90 \mathrm{~mm} \mathrm{Hg} .{ }^{6}$ This paper was largely ignored.

Now the topic of the relation between blood pressure reduction and the complications of hypertension has been reactivated. Traditionally doctors have tried to lower blood pressure to as near as possible to normal, but in March 1987 Cruickshank et al argued that the relation between mortality from coronary artery disease and the blood pressure achieved after treatment was J shaped - in other words, lowering the blood pressure too far caused extra deaths. ${ }^{7}$ In this issue (p 1227) Cruickshank suggests that excess deaths occur in patients with narrowing coronary arteries. In patients with no evidence of coronary heart disease the relation between mortality and the blood pressure achieved is not $\mathrm{J}$ shaped.

Other groups have also reported a $\mathrm{J}$ shaped curve,$^{8-10}$ and both the Glasgow Blood Pressure Clinic ${ }^{9}$ and the Department of Health and Social Security Hypertension Care Computing Group ${ }^{10}$ have observed it in patients with or without coronary ischaemia at presentation. This increased mortality was observed with diastolic pressures after treatment ranging from $80 \mathrm{~mm} \mathrm{Hg}$ to $90 \mathrm{~mm} \mathrm{Hg}$. It is not therefore resulting from extreme blood pressure reduction. The main problem with all these retrospective studies is that the quality of the data is often poor, relying on passing, often uninterested, junior doctors. Also despite the large size of the clinics the numbers of patients with coronary heart disease who require antihypertensive treatment and who achieve "excellent" control of blood pressure are small. The confidence intervals for their relative risk of death do not exclude the possibility that good rather than harm is being done. This statistical argument may, however, be offset by the consistency of the finding and the plausibility of the possible mechanismcritical reduction of blood flow through narrow coronary arteries in patients with low diastolic blood pressures.

Another possibility is that the benefits of reducing blood pressure may be offset by a harmful effect on other risk factors for coronary heart disease. Thiazide diuretics reduce blood pressure but adversely affect serum lipid concentrations. The
Glasgow group has shown, however, that its J shaped curve was independent of drug treatment, and in some trials thiazides have prevented rather than caused coronary artery disease. ${ }^{112}$ Some trials have specifically excluded patients with coronary heart disease, and they have not shown a J shaped curve. ${ }^{111314}$ In the elderly, among whom undiagnosed narrowing of the coronary arteries might be common, there have been two randomised trials that did not specifically exclude patients with coronary heart disease. One did not find a J shaped curve, ${ }^{15}$ and the other did. ${ }^{16}$ The second study reported a $J$ shaped curve irrespective of whether patients were allocated to drug treatment or to no treatment. ${ }^{17}$ This suggests that the excess deaths are not caused by the drugs.

To sustain his hypothesis that mortality is caused by preexisting heart disease Cruickshank has to disregard the reports from Glasgow and the computing group of a J shaped curve in patients with no previous heart disease. The Glasgow group thinks that its own data give "no direct support" to the idea that harm may be caused by attaining low diastolic pressures; they point out that the relation between achieved diastolic pressure and mortality from stroke is not $\mathrm{J}$ shaped. By contrast the computing group suggest that large falls in diastolic pressure "should be avoided," especially in men with a history of ischaemic heart disease. The two groups have similar results but come to opposite conclusions.

Doctors must be suspicious that they may drop blood pressure too low. Patients whose blood pressures are now "excellent" should be scrutinised carefully for heart disease. Furthermore, there is increasing evidence that when blood pressures are well controlled it may be possible to stop treatment with antihypertensive drugs without blood pressure rising..$^{18}$ Doctors should therefore attempt to reduce or discontinue drug treatment in patients whose pressures have become normal. Patients must be watched closely, and if pressures start to rise again treatment should be restarted. Finally, everybody agrees that patients who have diastolic blood pressures of more than $90 \mathrm{~mm} \mathrm{Hg}$ when they are being treated have a high mortality from coronary heart disease, and steps should thus be taken to improve control.

Reader in Medicine,

D G BEEVERS

Dudley Road Hospital, Birmingham B18 7QH

\footnotetext{
Ledingham JGG, Rajagopalan B. Cerebral complications in the treatment of accelerated hypertension. $Q \mathcal{F}$ Med 1979;48:25-41.

Cove DH, Seddon $M$, Fletcher RG, Dukes DC. Blindness after treatment for undiagnosed hypertension. Br Med $\mathcal{f} 1979 ;$ ii $245-6$.

Anonymous. Dangerous antihypertensive treatment [Editorial]. Br Med $\mathcal{J}$ 1979;ii:228-9.

4 Jackson G, Mahon W, Pierscianowski TA, Condon J. Inappropriate antihypertensive therapy in the elderly. Lancet 1976;ii:1317-9.
} 